\title{
Probabilistic Analysis of Seismic Hazard Posed by Mining Induced Events
}

\author{
S. Lasocki Department of Geophysics, Faculty of Geology, Geophysics and Environmental Protection, \\ AGH University of Science and Technology, Poland
}

The probabilistic seismic hazard analysis (PSHA) is a standard tool to estimate possible impacts of future earthquakes. Mining induced seismicity can also be a source of strong ground motion. The strongest events from copper mines in Legnica-Glogow Copper District in Poland, though still weak in comparison to earthquakes, gave rise to peak ground acceleration as high as $0.2 \mathrm{~g}$ and more. Differences between mining induced and natural seismic events, due to the link of the former to mining, mean, however, that the classic scheme of PSHA cannot be readily applied to induced seismicity problems. We have modified PSHA to take into account the facts that the seismic source zones in mines are transient and that the source size distribution is strongly non-linear. The final result of the analysis is a strong motion prediction related to a prescribed time period in the future. The modified PSHA is successfully applied in Poland to mitigate seismic risk posed by mining events. This paper presents the procedure and an example of its application for determining the design ground motion for a flotation wastes repository enlargement.

\section{INTRODUCTION}

According to the classic definition, a seismic hazard is any physical phenomenon associated with earthquake that has the potential to produce a loss (Aki and Lee, 2003). Since our present state of knowledge on the seismicity process is incomplete, we are forced to treat seismic events and their effects as partially random phenomena. As a result a preferred, though not exclusive, way to quantify the seismic hazard is a probabilistic approach (Cornell, 1968), in which the potential for strong ground motion or other hazardous effects is expressed in terms of the exceedance probability in a prescribed period. These potential results from properties of source, path and site (e.g. Cornell, 1968; Reiter, 1991; McGuire, 1993), are also assumed as probabilistic.

PSHA procedures for natural seismicity fill a generally accepted, four step scheme (e.g. Reiter 1991), namely:

- dividing the studied active region into source zones of statistically homogeneous seismic activity,

- evaluating probabilistic characteristics of the source zones,

- identifying local attenuation relations for the studied region,

- converting the probabilistic characteristics of seismicity through the attenuation relation into the exceedance probability of ground motion parameters at given points of the surface.

Unlike the earthquake process, the strain accumulation in mines, partially controlled by mining works, is time varying. Rockmass fracturing in an active zone is stationary unless conditions responsible for this process change. Activity of zones ceases after the mining operations to which the zones are linked, are terminated. New zones will appear at locations where mining commences. Hence, the source zones in mines are finite in both space and time and the seismic hazard no longer depends solely on the duration over which it is evaluated, but is also related to a specified time interval. However, the above scheme of PSHA cannot be readily applied to induced seismicity problems.

On the other hand, mining induced seismic events can also cause strong ground motion. In Poland's Legnica-
Glogow Copper District (LGCD), underground copper ore exploitation is accompanied by intense seismic activity. The strongest events, of magnitude more than 4 , are still weak compared to earthquakes but have been capable of producing, in the epicentral region, a peak ground acceleration (PGA) of $0.2 \mathrm{~g}$ or more. Moreover, in both the LGCD as well as in the Upper Silesian Coal Basin, the other region in Poland prone to mining induced seismicity, the seismic activity occurs directly beneath urbanized and industrialized areas.

Responding to growing needs, we have modified the classic PSHA to be applicable in mining induced seismicity problems (e.g. Lasocki, 2001a; Lasocki and Orlecka-Sikora, $2002 a, b)$. Results of the analysis are, in this case, predictions related to a prescribed time period in the future. The modified PSHA has been successfully applied to a number of problems of mitigating seismic risk posed by mining events. In this paper we outline the method and provide one example of its application to an actual practical problem from the LGCD area.

\section{PSHA FOR MINING INDUCED SEISMICITY}

Due to the transient character of source zones induced by mining, the PSHA scheme must be modified. The adjusted scheme comprises the following six steps:

- identifying source zones active in the past and determining their locations and times of activity,

- evaluating probabilistic characteristics for the zones active in the past,

- predicting locations and times of activity of the zones that will be active in the future time period under evaluation,

- predicting probabilistic characteristics of the future zones,

- identifying local attenuation relations for the studied region,

- converting the probabilistic characteristics of future zones' seismicity, through the attenuation relation, into the exceedance probability of ground motion parameters at given points of the surface in the period under evaluation. 


\subsection{Identifying Source Zones Active in the Past and Determining Their Probabilistic Characteristics}

Numerous and, in general, correctly parameterised mining seismic catalogues form an advantageous environment for PSHA in mining induced seismicity. Through analyses of these catalogues, one can unequivocally separate the source zones that were active in the past. Such a past zone is delineated by the area over which the events clustered and by the time period in which the seismic activity was more or less uniform (Orlecka-Sikora and Lasocki, 2002).

Probabilistic characteristics of the past zones are required in order to estimate the characteristics of source zones that are expected to activate in the future. Three probabilistic distributions of seismic parameters are needed in PSHA viz. the distributions of event occurrence frequency, event epicentre and source size. It is assumed that in the source zone, regardless of whether past or future, these distributions are unique and remain unchanged.

The distribution of the number of events in a constant time period (the event occurrence frequency) in a time-space zone is modelled by the Poisson's distribution. The probability of occurrence of $r$ events during time period of $D$ units is given by:

$$
\operatorname{Pr}(R=r, D)=\frac{(\lambda D)^{r}}{r !} e^{-\lambda D}
$$

where $\lambda$ is a distribution parameter estimated by the mean event rate.

In classic PSHA, it is usually assumed that epicentre locations are controlled by the uniform distribution over the source zone area. Such an assumption obviously disagrees with observed epicentre distributions in mines. Besides, it can unnecessarily complicate the practice of PSHA use. Therefore to represent the distributions of epicentre locations in past zones we accept the uniform distribution, discrete in the observed epicentres:

$$
f_{x y}(x, y)=\frac{1}{n_{\text {tot }}} \sum_{i=1}^{n_{\text {tot }}} \delta\left(x-x_{i}, y-y_{i}\right)
$$

where $n_{\text {tot }}$ is the number of events that occurred in the zone, $\left(x_{i}, y_{i}\right)$ are epicentre coordinates of these events and $\delta(\bullet, \bullet)$ is the two-dimensional Dirac's delta.

In Poland, the mining event size is parameterised by the seismic energy rather than by magnitude. In order to comply, however, with worldwide habits we represent here the event size by the common logarithm of energy, $m=\log E$, which has the same shape of probabilistic distribution as magnitude. Recent detailed investigations of induced seismicity have indicated that due to complexity and heterogeneity of the rockmass fracturing process, the magnitude distribution is often complex and multimodal. No presently known parametric model for magnitude can ensure the accuracy of actual mining data representation required in PSHA (Lasocki, 2001b). In this connection it was proposed to apply a modelfree, non-parametric estimator of $m=\log E$ density (e.g. Lasocki et al., 2000; 2002; Kijko et al., 2001, and the references therein). The density estimate is solely determined by observations. It turned out that an adaptive form of this estimator is particularly suitable for modelling the magnitude or $m=\log E$ distribution (Orlecka-Sikora and Lasocki, 2005). The adaptive estimator of the cumulative distribution function is:

$$
\hat{F}_{m}(m)=\frac{\sum_{i=1}^{n}\left[\Phi\left(\frac{m-m_{i}}{\omega_{i} h}\right)-\Phi\left(\frac{m_{\min }-m_{i}}{\omega_{i} h}\right)\right]}{\sum_{i=1}^{n}\left[\Phi\left(\frac{m_{\max }-m_{i}}{\omega_{i} h}\right)-\Phi\left(\frac{m_{\min }-m_{i}}{\omega_{i} h}\right)\right]}
$$

for $m_{\min } \leq m<m_{\max }$, zero for $m<m_{\min }$ and one for $m>m_{\text {max }}$ where $m_{\min }$ is the level of catalogue completeness, $n$ is the number of events greater than or equal to $m_{m i n}, m_{i}$ are sizes of these events, $m_{\max }$ is the upper limit of source size, $\Phi(\bullet)$ is the standard normal cumulative distribution, and the smoothing factor, $h$, and the weights, $\omega_{i}, i=1, . ., n$ are automatically selected to fit the data structure. The upper limit of source size, $m_{\max }$ which accounts for physical constraints on the source size, is estimated by:

$$
\hat{m}_{\max }=m_{\max }^{o b s}+\int_{m_{\min }}^{m_{\max }}\left[F_{m}(m)\right]^{n} d m
$$

where $m_{\max }^{o b s}=\log E_{\max }^{o b s}$ is the largest observed event size in the zone (the other symbols are as above) (e.g. Kijko and Graham, 1998). The estimator [4] is biased and the specific bias value is obtained from Monte Carlo simulations (Kwiatkowska, 2002). If all assumptions on homogeneity, stationarity and stochastic independency of events are satisfied, the events larger than $m_{\max }$ will never occur.

\subsection{Predicting Location, Activity Duration and Probabilistic Characteristics of Future Activity Source Zones}

The time-space zones that are expected to appear in the future are linked to areas and periods of future mining works. Thefuturezonelocations and activity durationsaredetermined from mining plans. It is assumed that the future zone will be active during the period of exploitation of a specified mining stope plus six months. The zone area is assumed to be equal to the stope area plus a $200 \mathrm{~m}$ margin around the stope (e.g. Cichy and Lasocki 1982, Drzęźla et al. 1991). If, in the studied region, there are zones of activity which do not directly accompany mining works (e.g. they are located in fault zones out of excavations), it is assumed that these zones will also remain active into the future.

The two-dimensional uniform distribution is supposed to control epicentre locations over the area of future source zones. In order to simplify numerical calculations, the continuous distribution is substituted by the discrete one. The zone area is covered with a dense net and it is assumed that the future event epicentres can only be located in the net nodes. The discrete probability distribution used for epicentre location is:

$$
\operatorname{Pr}\left\{x_{i}, y_{i}\right\}=1 / N
$$

where $N$ is the number of net nodes and $\left(x_{i}, y_{\mathrm{i}}\right), i=1, \ldots, N$, are the nodes coordinates. This simplification has a negligible effect on final PSHA results.

The source size characteristics for the future zones are estimated from the characteristics of the past zones. We still do not have a satisfactory method of interpolating and extrapolating functional representations of probability. Work on this subject is under way but at present we have to base PSHA on certain parameterisations of the source size probability distribution. There are two candidates for this purpose, namely the upper limit of source size, $m_{\text {max }^{\prime}}$ and the maximum possible event size, $m_{T}$. The upper limit of source size in a zone, $m_{\text {max }}$ represents the energy threshold, which neither the events that already occurred nor the events 
that will occur in the future can exceed. The mean return period for the event of size $m_{\max }$ is infinite. Since the natural seismicity is permanent, events of every size less than $m_{\max }$ will occur at some moment. Thus, $m_{\max }$ or its substitutes are of major importance to the seismic risk assessment in natural seismicity, in particular when the stability of long lifetime structures (e.g. nuclear power plants, nuclear waste repositories) is investigated. Such structures ought to be protected against the limiting value $m_{\max }$. In mining induced seismicity the duration of the source zone activity is, however, finite and not very long, usually from a few months to a few years. Hence, a hazard analysis based on $m_{\max }$ would lead to pessimistic estimates. If the expected duration of zone activity is $T$, then it is more realistic to scale hazard with the maximum possible event (that is the event of size $m_{T}$ ), whose mean return period equals $T$, rather than with the maximum probable event of infinite return period and size $m_{\max }$. The maximum possible event size, expected in $T$ time units in the future, $m_{T}$, is evaluated from the equation:

$$
T=\left\{\lambda\left[1-F_{m}\left(m_{T}\right)\right]\right\}^{-1}
$$

Scaling hazard with $m_{T}$ as the largest possible event size has, however, a certain dangerous disadvantage. Although events larger than $m_{T}$ will not, on average, occur in the zone, the probabilistic scatter about the average can make such events happen. Thus the ground motion could eventually be greater than the motion predicted with the use of $m_{T}$.

It is expected that future zones will repeat the probabilistic schemes of the closest in space and time past zones, which means that they will have the same $m_{T}$ and $m_{\max }$ values. If a predicted future zone location is near more than one past zone, then the estimates of $m_{T}$ and $m_{\max }$ are weighted averages of the parameter values for all neighbours. The weighting assumes that the similarity between the zone characteristics is inversely proportional to the distance (in space and time) between the zones. If the expected location of a future zone is far from the locations of past zones, then $m_{T}$ and $m_{\max }$ for the future zone are assessed from area maps of these parameters for the whole seismically active region. The maps are prepared using information about all past zones.

After this part of the analysis, every zone which is expected to become active in the future is described by:

- its location, determined by the distribution of net nodes linked to the planned location of mining in this part of the mine,

- its period of activity, $\left[t_{s^{\prime}} t_{e}\right]$, of length $T$, determined by the planned time period of mining in this region,

- the predicted maximum event size $m_{T}$ for the period of expected future zone activity, $\left[t_{s^{\prime}}, t_{e}\right]$;

- the predicted upper limit of event size $m_{\max }$.

\subsection{Local Attenuation Relations of Ground Motion}

Ground effects of mining events depend on the seismic source, seismic wave path and local soil conditions. These effects are usually modelled by the linear regression between the selected ground motion parameter, $a$, at point $(x, y)$, and the source size, $m$, and epicentral distance from the source to the point $(x, y), r$ :

$$
\log a(x, y)=\alpha+f(m)+g(r)+\delta(x, y)
$$

where $f(m)$ models the dependence of ground motion on source size, $g(r)$ models the dependence of ground motion on $r, \delta(x, y)$ models local site effects at $(x, y)$, and $\alpha$ is a constant (e.g. Seismological Research Letters, 1997; Douglas, 2003 and the references therein). The ground motion is usually parameterised with PGA components or spectral amplitudes of acceleration for selected natural frequencies (Douglas, 2003). Relations of type [7] are referred to as the attenuation relations. They account neither for the source directivity nor for the path anisotropy, while only occasionally taking into account the local site effects $(\delta(x, y))$. The neglected factors cause a dispersion of the actual values about the regression. The effect is quantified by the residual variance of regression.

Seismic sources in mines are relatively weak; hence their ground effects quickly decrease with increasing $r$. The attenuation relation for a limited area is strongly linked to the specific conditions of wave propagation in this region. Thus, it is recommended that locally valid attenuation relations be worked out, identified by ground motion data from such a limited region. Before the recorded ground motions are parameterised in terms of PGA, the signals are usually subjected to a low-pass filter with a cut-off frequency of about $10 \mathrm{~Hz}$, to remove higher frequency components that are unimportant for engineering purposes. The locally valid attenuation relations, identified by local ground motion data, are also the most efficient way to decrease the uncertainty of the ground motion estimates, caused by heterogeneity of the propagation medium.

In his extensive review, Douglas (2003) discusses various forms of $f(m)$ and $g(r)$ functions and other problems connected with identification of the regression relation [7]. Table 1 presents models of type [7], which we usually try in actual problems.

Given values of the independent variables, $m$ and $r$, relations of type [7] predict the median value of $\log a(x, y)$, that is the ground motion parameter value whose exceedance probability is $50 \%$. The dispersion about the regression lines are represented by the confidence intervals for prediction. The limits of $(1-2 p)$ probable confidence intervals for prediction of $\log a$ values are given by:

$$
\begin{aligned}
& \log a(x, y)=\alpha+f(m)+g(r) \\
& \pm t_{p}(s-v-1) \sqrt{\mathbf{X}^{\mathbf{T}} \mathbf{C}_{\mathbf{b}} \mathbf{X}+S E E^{2}}
\end{aligned}
$$

where $s$ is the number of ground motion data used to identify the attenuation relation, $v$ is the number of independent variables, $t_{p}(s-v-1)$ is the critical value of Student's distribution for $(s-v-1)$ degrees of freedom, $\mathbf{X}$ is the vector, whose first component is 1 , and the others equal the independent variable values for $\left(x_{0}, y_{0}\right), \mathbf{X}^{\mathrm{T}}$ is its transposition, $\mathbf{C}_{\mathbf{b}}$ is the covariance matrix of regression coefficient estimators and $S E E$ is the standard error of estimate. If $s-v-1$ is large, greater than $\sim 30$, the critical value $t_{p}(s-v-1)$ can be approximated by the critical value of standard normal distribution, $z_{p}$.

\subsection{Ground Motion Prediction}

In the last step of the analysis the results of the previous steps are integrated to obtain probabilistic characteristics of the selected ground motion parameter, predicted at given points for the time interval of prediction. The probability that, due to the activity of $k$-th seismic zone, PGA at point $\left(x_{0}, y_{0}\right)$ will exceed the given value, $a_{\max }$ is:

$$
\begin{aligned}
& \operatorname{Pr}_{k}\left(a \geq a_{\max }\right)= \\
& \int_{r_{\min }(k)}^{r_{\max }{ }^{(k)}} \int_{m_{\min }}^{m_{\max }{ }^{(k)}} f_{r}(r) f(m \mid n \neq 0, D) \operatorname{Pr}\left(a \geq a_{\max } \mid m, r\right) d m d r
\end{aligned}
$$

where $D$ is the duration of the interval of prediction, $f_{\mathrm{r}}(r)$ is the distribution of epicentral distance to $\left(x_{0}, y_{0}\right)$, implied by the uniform distribution of epicentres in the seismic zone, 
TABLE 1 Models of ground motion attenuation relation

\begin{tabular}{|c|c|c|c|c|}
\hline Model & $f(m)$ & $g(r)$ & $\delta(x, y)$ & $\begin{array}{l}\text { Regression } \\
\text { coefficients }\end{array}$ \\
\hline Linear & $\beta m$ & $\gamma \log r$ & $=0$ & $\beta, \gamma$ \\
\hline Linear with amplification at selected locations & $\beta m$ & $\gamma \log r$ & $\neq 0$ & $\beta, \gamma, \delta$ \\
\hline Non-linear in the epicentral zone & $\beta m$ & $0.5 \gamma \log \left(r^{2}+h^{2}\right)$ & $=0$ & $\beta, \gamma, h$ \\
\hline $\begin{array}{l}\text { Non-linear in the epicentral zone with amplification at } \\
\text { selected locations }\end{array}$ & $\beta m$ & $0.5 \gamma \log \left(r^{2}+h^{2}\right)$ & $\neq 0$ & $\beta, \gamma, h, \delta$ \\
\hline With inelastic attenuation & $\beta m$ & $\gamma \log r+\gamma_{1} r$ & $=0$ & $\beta, \gamma, \gamma_{1}$ \\
\hline With non-linear dependence on source size & $\beta m+\beta_{I} m^{2}$ & $\gamma \log r$ & $=0$ & $\beta, \beta_{1}, \gamma$ \\
\hline $\begin{array}{l}\text { With non-linear dependence on source size and inelastic } \\
\text { attenuation }\end{array}$ & $\beta m+\beta_{I} m^{2}$ & $\gamma \log r+\gamma_{1} r$ & $=0$ & $\beta, \beta_{1}, \gamma, \gamma_{1}$ \\
\hline Bi-linear & $\begin{array}{l}\beta m \text { for } a \leq a_{c} \\
\beta^{\prime} m \text { for } a>a_{c}\end{array}$ & $\begin{array}{l}\gamma \log r \text { for } a \leq a_{c} \\
\gamma^{\prime} \log r \text { for } a>a_{c}\end{array}$ & $=0$ & $\beta, \gamma, \beta^{\prime}, \gamma^{\prime}, a_{c}$ \\
\hline
\end{tabular}

$r_{\min }{ }^{(\mathrm{k})}$ and $r_{\max }{ }^{(\mathrm{k})}$ are the limits of epicentral distance range, $m_{\text {min }}$ and $m_{\max }{ }^{\text {min }}$ are the catalogue completeness threshold and upper limit of event size in the zone, respectively, $f(m \mid n \neq 0, D)$ is the source size distribution, conditional upon the event occurrence in the zone, and is given by:

$$
\begin{aligned}
& f(m \mid n \neq 0, D)= \\
& \frac{\lambda D f_{m}(m) \exp \left\{-\lambda D\left[1-F_{m}(m)\right]\right\}}{1-\exp (-\lambda D)}
\end{aligned}
$$

where $\lambda$ is the mean event rate in the zone, $f_{m}(m)$ and $F_{m}(m)$ are the probability density and cumulative distribution of source size in the zone, respectively. To simplify notation in [9] it is assumed that the zone activity period includes the time interval of prediction. In other cases, some obvious modifications are necessary. It is also assumed that the catalogue completeness level, $m_{\text {min }}$ is the same for all zones.

The exceedance probability of $a_{\max }$ conditional upon occurrence of an event of size $m$ at the distance $r$, $\operatorname{Pr}\left(a \geq a_{\max } \mid m, r\right)$, results directly from probabilistic properties of the attenuation relation [8] and takes the form of:

$$
\operatorname{Pr}\left(a \geq a_{\max } \mid m, r\right)=1-F_{t}\left[t\left(a_{\max }, r, m\right), s-v-1\right]
$$

where $F_{t}(t, v)$ is the Student's cumulative distribution withv degrees of freedom. The term $t\left(a_{\max ^{\prime}} r, m\right)$ is given by:

$$
t\left(a_{\max }, r, m\right)=\frac{\log a_{\max }-\alpha-f(m)-g(r)}{\sqrt{\mathbf{X}^{T} \mathbf{C}_{\mathbf{b}} \mathbf{X}+S E E^{2}}}
$$

Other symbols are as in equation [8].

Relationship [9] incorporates all kinds of uncertainty present in the considered problem. $f_{r}(r)$ accounts for the source location uncertainty. The uncertainty of source size of the event to occur is represented by $f(m \mid n \neq 0, D)$. $\operatorname{Pr}\left(a \geq a_{\max } \mid m, r\right)$ accounts for the uncertainty of ground motion amplitude, given the source size and location. When one expects $L$ seismic zones to appear, the probability that during the time interval of prediction of length $D$, PGA greater than or equal to $a_{\max }$ will occur, is given by:

$$
\operatorname{Pr}\left(a \geq a_{\max } \mid D\right)=1-\prod_{k=1}^{L}\left[1-\operatorname{Pr}_{k}\left(a \geq a_{\max }\right)\right]
$$

As mentioned in Section 2.2, a method of estimating functional nonparametric probability characteristics of future zones is not yet completed and the present PSHA for mining induced seismicity assumes that the largest event in the zone in the time interval of prediction will have size $m_{D}$ This, and the assumption on epicentre distribution, [5], lead to the simplification of [9] to:

$$
\begin{aligned}
& \operatorname{Pr}_{k}\left(a \geq a_{\max }\right)= \\
& \frac{1}{N^{(k)}} \sum_{i=1}^{N^{(k)}}\left[1-F_{t}\left(t\left(a_{\max }, r_{i}{ }^{(k)}, m_{T}{ }^{(k)}\right)\right)\right]
\end{aligned}
$$

where $\left(x_{i}, y_{\mathrm{i}}\right), \quad i=1, \ldots, N^{(k)}$ are node coordinates of the net with which the $k$-th zone area is covered, and $r_{i}^{(k)}=\sqrt{\left(x_{i}-x_{o}\right)^{2}+\left(y_{i}-y_{o}\right)^{2}}$. PGA values of a prescribed exceedance probability, say $p$, are assessed by solving the equation

$$
\sum_{k=1}^{L} \ln \frac{1-\operatorname{Pr}_{k}\left(a \geq a_{\max }\right)}{(1-p)^{1 / L}}=0
$$

for the unknown $a_{\max }$ where $\ln$ stands for the natural logarithm

\section{AN EXAMPLE OF APPLICATION}

The application of PSHA to mining induced seismicity can be illustrated by a recent project involving the enlargement of a wastes repository. The Polish copper industry, which is engaged in both the underground exploitation of copperore and ore processing, is located in the Legnica-Głogów Copper District (LGCD) in south-west Poland. Ore flotation concentrate accounts for barely 6 per-cent of the excavated ore. The remainder is waste which presently amounts to some 26 million tons per annum (Jasiński and Janicki, 2003). Since 1977 the waste has been dumped into the Żelazny Most repository, which is one of the largest mineral waste dumps in the world. The repository covers an area of about 12.4 $\mathrm{km}^{2}$ and is enclosed within a $14 \mathrm{~km}$ long by $40 \mathrm{~m}$ high earth dam containing 343 million $\mathrm{m}^{3}$ of waste (as of year-end 2002 (Jasiński and Janicki, 2003)). As the repository fills, additional capacity is gained through raising the dam (Lewiński and Wolski, 1996). Recent development plans include raising the dam by a further $40 \mathrm{~m}$ in the next few years. 
LGCD is an area of intense seismic activity connected with mining operations in three underground copper mines: Rudna, Polkowice-Sieroszowice and Lubin. The copper ore is extracted from hard rocks at considerable depths, from 800 to 1100 meters below the surface. The mine seismicity networks record several thousand events of the local magnitude range between 0.4 and 4.5 annually. Instrument observation of ground motion indicated that stronger events could result in PGAs as high as $2.0 \mathrm{~m} / \mathrm{s}^{2}$. Such an impact could disrupt the repository dam's stability, which could lead to catastrophic consequences for both production and environment. It has been decided, therefore, to carry out a PSHA project aimed at determining design parameters of ground motion for the elazny Most repository enlargement (Lasocki et al., 2003). The objective of the project was to predict limiting values of horizontal, $a_{x y^{\prime}}$ and vertical, $a_{z^{\prime}}$ PGA (PHA and PVA respectively) along the repository dam for the years 20032028. The limiting values were determined as those whose exceedance probability in the time period under study was 0.1 (10 percent).

Based on the mine seismicity catalogues from the last 20-25 years, 99 time-space source zones of past-to present activity were singled out and their probabilistic characteristics were determined. The spatial distribution of the zones of past activity is show in Figure 1. The distribution of the upper limit of source size, $m_{\max }$, over the LGCD area, constructed from the individual $m_{\max }$ values of the identified zones, is presented in Figure 2. The upper limit of source size represents a maximal potential ability of the rockmass to release the strain energy in a single event. Hence, it can be seen that stronger events can be expected to occur just to the west of the repository.

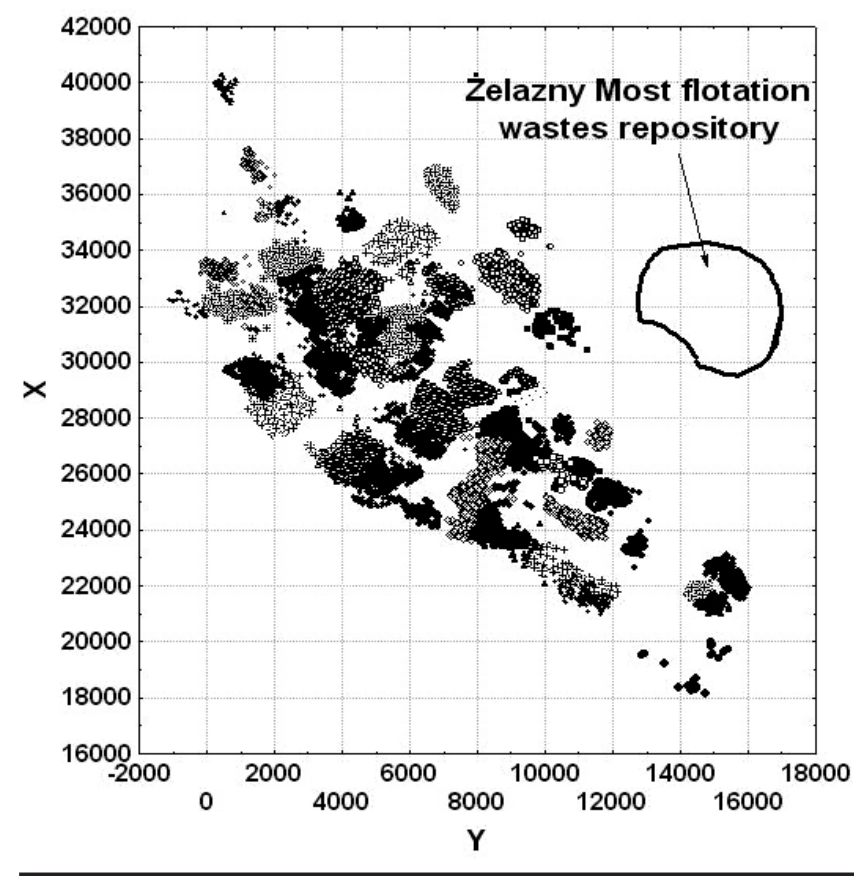

FIG. 1 Time-space source zones of past seismic activity in LGCD

Prediction of future zone locations and periods of activity was based on integrated programs of mining works. In this way, 67 zones of expected future activity were determined. Next, their probabilistic features were deduced from the characteristics of the past zones.

Ground motion at the repository dam has been monitored for a few years, first with three uniaxial electromagnetic velocity sensors and, since 2002, with three accelerometer stations located at different points along the dam.

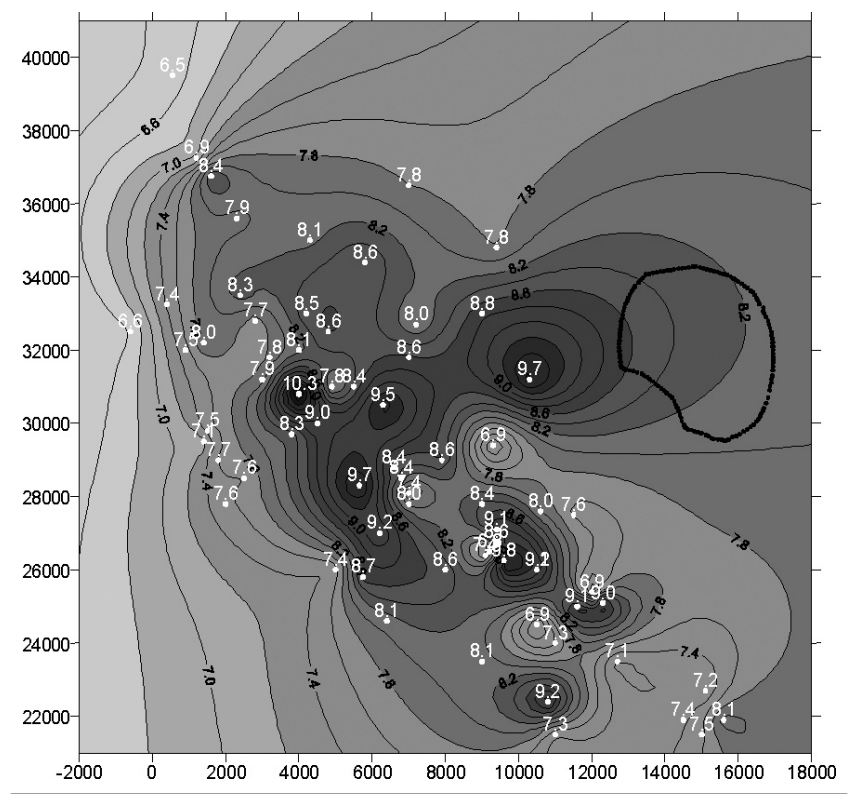

FIG. 2 Distribution of the upper limit of source size over the LGCD area

Every station is equipped with two triaxial accelerometers installed in the ground at the base and on the crown of the dam. In order to ensure a strict connection between the attenuation relations and the local propagation conditions, the data from the dam were used exclusively to construct the relations. Altogether 108 three-component acceleration signals induced by 26 seismic events and 161 one-component velocity signals induced by 40 events were processed.

The attenuation relation for both studied ground motion parameters, $a_{x y}$ and $a_{z^{\prime}}$, were identified by standard regression analysis. The analysis requires the data sample to be homogeneous and malfunctions when the sample consists of data groups that significantly differ from one another in the response of the dependent variable to the same values of the independent variables. The analysed ground motion data originated from seismic events that occurred at distances of between a few hundred meters to more than ten thousand meters from the sensors and was collected by different instruments at different locations. These factors could cause non-homogeneity in the data sample. The homogeneity of the data was studied using the analysis of variance of residuals. Surprisingly it turned out that PHA values recorded at the base and crown of the dam did not differ from each other, whereas the PVA values were amplified at the crown. It was also established that attenuation of ground motion from near and far events was different and a selection criterion $(r<7000 \mathrm{~m})$ was applied to the input data. The final attenuation relations of $a_{x y}$ and $a_{z^{\prime}}$ were:

$$
\begin{gathered}
\log a_{x y}=1.2+0.42 m-1.58 \log \sqrt{r^{2}+(593)^{2}} \\
\log a_{z}=0.67+0.36 m-1.39 \log r
\end{gathered}
$$

Figure 3 presents the limiting values of PHA along the repository dam predicted for the time period 2003-2028, which are the final result of PSHA. The largest value is $1.25 \mathrm{~m} / \mathrm{s}^{2}$. The prediction of PVA is the same shape but the maximum value is nearly half, equal to $0.65 \mathrm{~m} / \mathrm{s}^{2}$. 


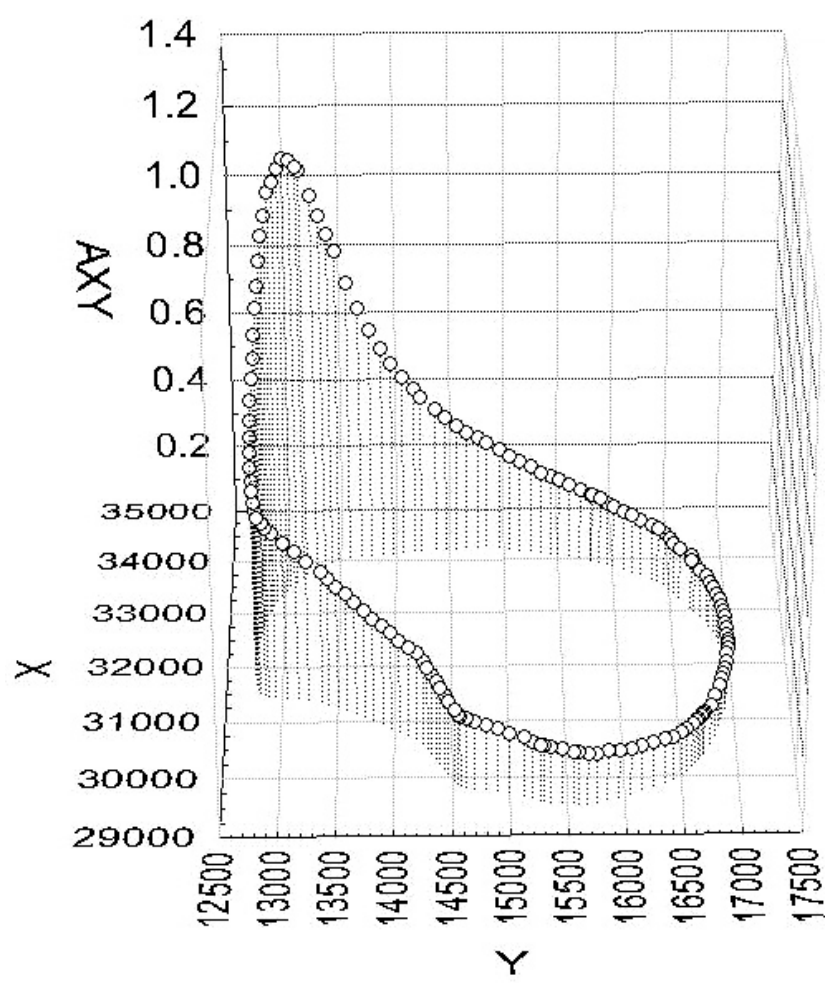

FIG. 3 Predicted limiting PHA values along the repository dam for the years 2003-2028

PSHA allows consideration of different hazard scenarios. In the problems studied, we analysed individual impacts of 12 future source zones that were expected to occur close to the repository. As a result we identified the zone whose share in the seismic hazard of the repository was the largest and most decisive. If it were decided that this particular zone would not be mined in the future, the largest limiting PHA, expected in 2003-2028, would drop down to $0.46 \mathrm{~m} / \mathrm{s}^{2}$.

\section{CONCLUSIONS}

After some modifications, the probabilistic seismic hazard analysis can also be applied to estimate the hazard posed by mining induced seismicity. First of all, both the event generation process and the seismic hazard are not stationary. Seismic catalogues are used to identify zones of past activity and to determine their dimensions in both space and time. Future activity is expected to occur in the vicinity of future mining stopes. Therefore mining plans are necessary components of input data for the analysis of hazard due to mining induced seismic events. These plans are used to predict the time-space locations of zones of future activity and the probabilistic properties of such zones are estimated from the probabilistic characteristics of the past zones. In this way, the result of probabilistic seismic hazard analyses for mining induced seismicity is the prediction of ground motion related to a prescribed area and time period.

\section{ACKNOWLEDGMENTS}

This paper was elaborated within the framework of a research project No. 11.11.140.06 of the Faculty of Geology, Geophysics and Environmental Protection, AGH University of Science and Technology, Kraków, funded by the Polish State Committee for Scientific Research. The author wishes also to express his sincere thanks to two anonymous reviewers of this paper.

\section{REFERENCES}

Aki, K. and Lee, W.H.K. (2003) Glossary of Interest to Earthquakes and Engineering Seismologist. Appendix 1 in International Handbook of Earthquake and Engineering Seismology, Part B (eds. W.H.K. Lee, H. Kanamori, P.C. Jennings, C. Kisslinger), Academic Press, London, San Diego, Burlington, pp. 1793-1856.

Cichy, A. and Lasocki, S. (1982) Some possibilities of statistical interpreting mining microseismological data from the point of view of estimating rockburst danger. Publs. Inst. Geophys. Pol. Acad. Sci. M-5 (155): pp. 85-100 (in Polish with English abstract and figure captions).

Cornell, C.A. (1968) Engineering seismic risk analysis. Bull Seismol. Soc. Am 58: pp. 1583-1606.

Douglas, J. (2003) Earthquake ground motion estimation using strong-motion records: a review of equations for the estimation of peak ground acceleration and response spectral ordinates. Earth-Science Rev. 61: pp. 43-104.

Drzęźla, B., Białek, J., Jaworski, A., Bańka, P. and Słapa, W. (1991) Distributions of the number and energy of mining shocks nearby active longwall excavations. Publs. Inst. Geophys. Pol. Acad. Sci. M-15 (235): pp. 197-202 (in Polish with English abstract and figure captions).

Jasiński, A. and Janicki, K. (2003) Geological Conditions of Influence of Żelazny Most Tailings Dump on Subsurface Water. In Proc. Symp. Warsztaty Górnicze, Szklarska Poręba 26-28 May 2003, (ed. E. Pilecka), Wyd. IGSMiE PAN, Kraków, pp. 89-104 (in Polish).

Kijko, A. and Graham, G. (1998) "Parametric-Historic" procedure for probabilistic seismic hazard analysis. Part I: Assessment of maximum regional magnitude mmax. Pure Appl. Geophys. 152: pp. 413-442.

Kijko, A., Lasocki, S. and Graham, G. (2001) Nonparametric seismic hazard analysis in mines. Pure Appl. Geophys. 158: pp. 1655-1676.

Kwiatkowska, I. (2002) Bias Assessment of the Nonparametric mmax Estimator With the Use of Computer Simulations. Unpublished MSc. Project, Faculty of Geology, Geophysics and Environmental Protection, AGH University of Science and Technology, Krakow, Poland (in Polish)

Lasocki, S. (2001a) Probabilistic Seismic Hazard Analysis for Induced Seismicity and Its Use for Predicting Peak Ground Acceleration at Żelazny Most Depository. In Abstracts 28th Polish-Czech-Slovakian Symposium on Mining Geophysics, Niedzica, 11-13 June 2001, Sosnowiec, Poland, p. 2.

Lasocki, S. (2001b) Quantitative Evidences of Complexity of Magnitude Distribution in Mining-induced Seismicity: Implications for Hazard Evaluation. In 5th Int. Symp. Rockbursts and Seismicity in Mines "Dynamic rockmass response to mining", Magalisberg, 17-20 September 2001 (eds. G. van Aswegen, R.J. Durrheim, W.D. Ortlepp) SAIMM S27, Johannesburg, South Africa, pp. 543-550.

Lasocki, S. and Orlecka-Sikora, B. (2002a) Prediction of Soil Vibrations for Polkowice in 2001-2013. In Proc. XXV Winter School of Rock Mechanics, Zakopane, 18-22 March 2002 (ed. D. Flisiak), Wyd. Katedry Geomechaniki, Budownictwa i Geotechniki AGH, Kraków, Poland, pp. 369-384. (in Polish with English abstract and figure captions).

Lasocki, S. and Orlecka-Sikora, B. (2002b) Probabilistic Seismic Hazard Analysis for Time-varying Seismicity: an Example From LegnicaGlogow Seismically Active Mining Area. In Book of Abstracts XXVIII Gen. Assem. ESC, Genoa, 01-06 September, Italy, p. 259.

Lasocki, S., Kijko, A. and Graham, G. (2000) Model-free Seismic Hazard Estimation. In Proc. Int. Conf. Earthquake Hazard and Risk in the Mediterranean Region, EHRMR'99, Lefkosa, 18-22 November1999 (ed. H. Gokcekus) Educational Foundation of Near East University, Lefkosa, T. R. N. Cyprus, pp. 503-508.

Lasocki, S., Kijko, A. and Graham, G. (2002) Model-free Seismic Hazard Analysis. In Seismogenic Process Monitoring. (eds. H. Ogasawara, T Yanagidani, and M. Ando). Balkema, Lisse, pp. 327-339.

Lasocki, S., Kłeczek, Z., Mirek, J., Olszewska, D., Orlecka-Sikora, B. and Gibowicz, S.J. (2003) Prediction of Seismic Impact on "Żelazny Most" Repository With a Use of Acceleration Ground Motion Data. KGHM „Polska Miedź" S.A., Hydrotechnical Division - Final Project Report (unpublished).

Lewiński, J. and Wolski, W., eds. (1996) Part V - Waste Repositories. In Monograph of KGHM Polska Miedź S.A. (ed. A. Piestrzyński.), CBPM "Cuprum” Sp. z o.o., Wrocław, pp. 787-912 (in Polish).

McGuire, R.K. (1993) Computations of seismic hazard. Ann. Geof. 36: pp $181-200$

Orlecka-Sikora, B. and Lasocki, S. (2002) Clustered structure of seismicity from Legnica-Głogów Copper District. Publs. Inst. Geophys. Pol. Acad Sci. M-24 (340): pp. 105-119 (in Polish with English abstract and figure captions).

Orlecka-Sikora, B. and Lasocki, S. (2005) Nonparametric Characterization of Mining Induced Seismic Sources. In Proc. RaSiM6 - 6th Int. Symp. Rockburst and Seismicity in Mines, Y. Potvin and M.R. Hudyma (eds.), Australian Centre for Geomechanics, March 2005.

Reiter, L. (1991) Earthquake Hazard Analysis. Columbia University Press, New York.

Seismological Research Letters (1997), 68, No.1 